\title{
Kinetics and mechanism of electron-transfer reactions: Oxidation of butanone and cyclohexanone by thallium (III) in acid perchlorate medium- an appraisal of keto form reactivity
}

\author{
Shalini Hemkar ${ }^{1}$, Riya Sailani ${ }^{2,}{ }^{*}$, Chandra Lata Khandelwal ${ }^{2}$, Prem Dutt Sharma ${ }^{2}$ \\ ${ }^{1}$ Department of Chemistry, Government College, Churu, Rajasthan \\ ${ }^{2}$ Department of Chemistry, University of Rajasthan, Jaipur - 302055 (India)
}

Email address:

1.p_riya@yahoo.co.in (R. Sailani)

\section{To cite this article:}

Shalini Hemkar, Riya Sailani, Chandra Lata Khandelwal, Prem Dutt Sharma. Kinetics and Mechanism of Electron-Transfer Reactions: Oxidation of Butanone and Cyclohexanone by Thallium (III) in Acid Perchlorate Medium- An Appraisal of Keto Form Reactivity. American Journal of Physical Chemistry. Vol. 2, No. 5, 2013, pp. 73-79. doi: 10.11648/j.ajpc.20130205.11

\begin{abstract}
The kinetics of oxidation of ketones by thallium (III) has been studied in acid perchlorate medium. The reaction does not indicate enolization to be the rate controlling step in the reaction mechanism. The kinetic rate law (1) has been observed. $-\frac{\mathrm{d}\left[\mathrm{Tl} l^{\mathrm{III}}\right]}{\mathrm{dt}}=\frac{\mathrm{k}_{1} \mathrm{~K}_{\mathrm{h}}[\mathrm{Tl}(\mathrm{III}) \text { ketone }]}{\left[\mathrm{H}^{+}\right]+\mathrm{K}_{\mathrm{h}}}$ Where $\mathrm{K}_{\mathrm{h}}$ is the hydrolysis constant of the oxidant. A plausible reaction
\end{abstract} mechanism is suggested conforming to the rate law (1). Activation parameters were evaluated.

Keywords: Kinetics, Mechanism, Oxidation, Butanone, Cyclohexanone, Thallium (III)

\section{Introduction}

The mechanism of oxidation of ketones can not be considered to be completely established either for thallium (III) or other oxidants [1-13]. It is still an open question to settle whether it is nucleophilic addition or substitution on the -carbon atom which is associated with oxidation. Therefore, it necessitated to explore this problem to arrive at some logical conclusions. Another important reason to knack this problem is related to the intervention of carbonyl compounds which are generally intermediates in such oxidation reactions.

Enolization has generally been observed to be the rate determining step in oxidation of ketones in acid medium $[10,11]$. Also, there are reports of radical mechanism in certain reactions. Quite different mechanisms have been reported for the oxidation of ketones by permanganate [1013]. In one case the rate dependence has been attributed to hydrogen ion concentration via protonation of the permanganate ion and to enolization of the ketone. On the other hand formation of an intermediate complex in the pre-equilibrium step has been assumed ${ }^{10}$ that decomposes to the end products in rate-determining step. Also, a large number of metal ion catalyzed oxidation of ketones are reported. [14-16]

Considering all these observations the kinetics of oxidation of butanone and cyclohexanone by - a two equivalent oxidant such as thallium (III) was undertaken in acid perchlorate medium. These reactions also further tempted us from the following view points:

First thallium (III) is considered to be a better oxidant in the light of moderately high redox potential [17] of $\mathrm{Tl}^{3+} / \mathrm{Tl}^{+}(\sim 1.25 \mathrm{~V})$. Also, $\mathrm{Tl}^{3+}\left(5 \mathrm{~d}^{10}\right)$ forms organometallic derivatives, its reduced state $\mathrm{Tl}^{+}\left(5 \mathrm{~d}^{10} 6 \mathrm{~s}^{2}\right)$ with inert pair despite being highly stable exhibits least tendency of coordination. Thus $\mathrm{Tl}^{3+}$ makes an ideal choice as an oxidant to probe its interactions with ketones to discriminate between ketone or its enol forms to be reactive forms.

Secondly $\mathrm{Tl}^{2+}$ is now well established intermediate oxidation state of $\mathrm{Tl}^{3+}$. If an evidence regarding participation of a free radical of the substrate is established, the formation of $\mathrm{Tl}^{2+}$ in the reaction will be very useful event for logical proposition of the reaction mechanism.

Thirdly whether or not enolization plays any role in the kinetics of oxidation of ketones by thallium (III). 


\section{Experimental}

Thallic perchlorate solution was prepared by dissolving thallic oxide, $\mathrm{Tl}_{2} \mathrm{O}_{3}$ (Fluka) in perchloric acid $(70 \%$, E.Merck) on heating. The solution was left overnight and then decanted,the latter after dilution was standardized iodometrically $[17,18]$. All other reagents were either of AnalaR or guaranteed reagent grade and were used as supplied.

Doubly distilled water was employed throughout the study; the second distillation was from alkaline permanganate solution in an all glass assembly.

Kinetics was carried out in glass stoppered Erlenmeyer flasks which were suspended in a water-bath thermostated at the desired temperature to within $\pm 0.1^{\circ} \mathrm{C}$ unless mentioned otherwise. All ingredients of the reaction mixture of required concentrations except thallium (III) were taken in these flasks; the requisite volume of temperature pre-equilibrated thallium (III) solution was added in the end to initiate the reactions. However, order of mixing does not affect the kinetics. An aliquot (5 or 10 $\mathrm{cm}^{3}$ ) of the reaction mixture was withdrawn and then discharged into freshly prepared ice cold admixture of $(\sim 10 \%) \mathrm{KI}$ and $\left(\sim 1.0 \mathrm{~mol} \mathrm{dm}^{-3}\right)$ acid. The liberated iodine was titrated against thiosulphate solution employing starch as an indicator. The titrating mixture was vigorously stirred at each addition of thiosulphate to avoid any iodine adsorption on precipitated thallous iodide.

Initial rates were computed [19] employing plane mirror method. Pseudo first order rate constants were also calculated wherever reaction conditions such as [Ketone] $>>10$ [Tl (III)] were held. Second order plots were also made wherever concentrations of the reactants were comparable. Triplicate rate measurements were reproducible to within $\pm 5 \%$.

\subsection{Stoichiometry and Product Analysis}

The kinetics was studied under pseudo first order conditions where sufficiently large excess of concentration of ketone over that of the oxidant was maintained. Since the product analysis is an important aspect of the stoichiometry, the reactions both for ethylmethylketone and cyclohexanone [4] in excess over thallium (III) in acid perchlorate medium were allowed to occur in a thermostated water bath at $40 \pm 0.1^{\circ} \mathrm{C}$ for ca. $8 \mathrm{~h}$. The products in each case were extracted by diethylether and 2,4-dinitrophenylhydrazine solution in $2 \mathrm{~mol} \mathrm{dm}^{-3} \mathrm{HCl}$ was added in each case. However, no precipitate was obtained in case of ethylmethylketone whereas yellow precipitate on standing overnight appeared in case of cyclohexanone product. Qualitative test of acetic acid shows its presence in case of ethylmethylketone. Thus the stoichiometry of these reactions correspond to the reactions as represented by eqns(I) and (II) respectively.
Also a few reactions with excess of thallium (III) concentration over ketones were similarly allowed to react. Excess of [Tl (III)] was determined iodometrically after ensuring completion of the reaction. These results exhibit stoichiometry corresponding to reaction of one mole of ketone with a mole of ketone.

$$
\mathrm{CH}_{3} \mathrm{COC}_{2} \mathrm{H}_{5}+\mathrm{Tl}(\mathrm{III}) \stackrel{\mathrm{H}_{2} \mathrm{O}}{\longrightarrow} \mathrm{CH}_{3} \mathrm{CO}_{2} \mathrm{H}+\mathrm{Tl}(\mathrm{I})+2 \mathrm{H}^{+}
$$

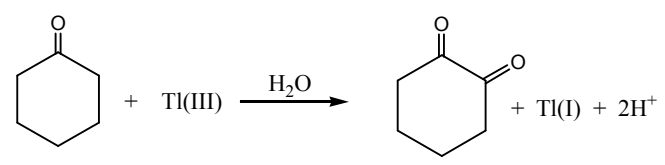

\section{Results}

\subsection{Thallium (III) Dependence}

Thallium (III) concentration was varied in the range $(1.0-5.0) \times 10^{-3} \mathrm{~mol} \mathrm{dm}^{-3}$ at fixed concentration of butanone and cyclohexanone respectively and $\left[\mathrm{H}^{+}\right]=0.5 \mathrm{~mol} \mathrm{dm}^{-3}$. Pseudo first order rate constants were found to be independent of the initial concentrations of thallium (III). However, initial rates were also evaluated in a few cases to confirm whether or not order with respect to the oxidant is one, the rates were found to be proportionately dependent on the initial concentrations of thallium (III). Such observations certainly ruled out any possibility of zero order dependence with respect to thallium (III).

\subsection{Ketone Concentration Dependence}

The concentration of butanone was varied at fixed concentrations of thallium (III) viz. $2.0 \times 10^{-3}$ and $3.0 \times 10^{-3}$ mol dm${ }^{-3}$ respectively.

Pseudo first order rate constants $\left(\mathrm{k}^{\prime}, \mathrm{s}^{-1}\right)$ were calculated and a plot of $\mathrm{k}^{\prime}$ versus [butanone] yielded a straight line passing through the origin confirming first order with respect to butanone. The concentration of cyclohexanone was varied in the range $(0.5-5.0) \times 10^{-2} \mathrm{~mol} \mathrm{dm}^{-3}$ at fixed concentrations of other reaction ingredients. Initial rates $\left(\mathrm{k}_{\mathrm{i}}\right.$, mol $\mathrm{dm}^{-3} \mathrm{~s}^{-1}$ ) were evaluated and a plot of $\mathrm{k}_{\mathrm{i}}$ versus [cyclohexanone] yielded a straight line passing through the origin further confirming first order dependence with respect to cyclohexanone.

Further to verify overall order of the reaction, second order plots were also made (Figs.1 and 2) for comparable concentrations of the oxidant and substrates such as log $\left(\left[\mathrm{Tl}^{\mathrm{III}}\right]_{\mathrm{t}} /[\text { Ketone }]_{\mathrm{t}}\right)$ or log $\left([\text { Ketone }]_{\mathrm{t}} /\left[\mathrm{Tl}^{\mathrm{III}}\right]_{\mathrm{t}}\right)$ versus time and the second order rate constants $\left(\mathrm{k}, \mathrm{dm}^{3} \mathrm{~mol}^{-1} \mathrm{~s}^{-1}\right)$ calculated from these plots were in excellent agreement with those obtained from initial rates and pseudo first order rate constants respectively. Such an agreement also confirms second order nature of the reactions. 

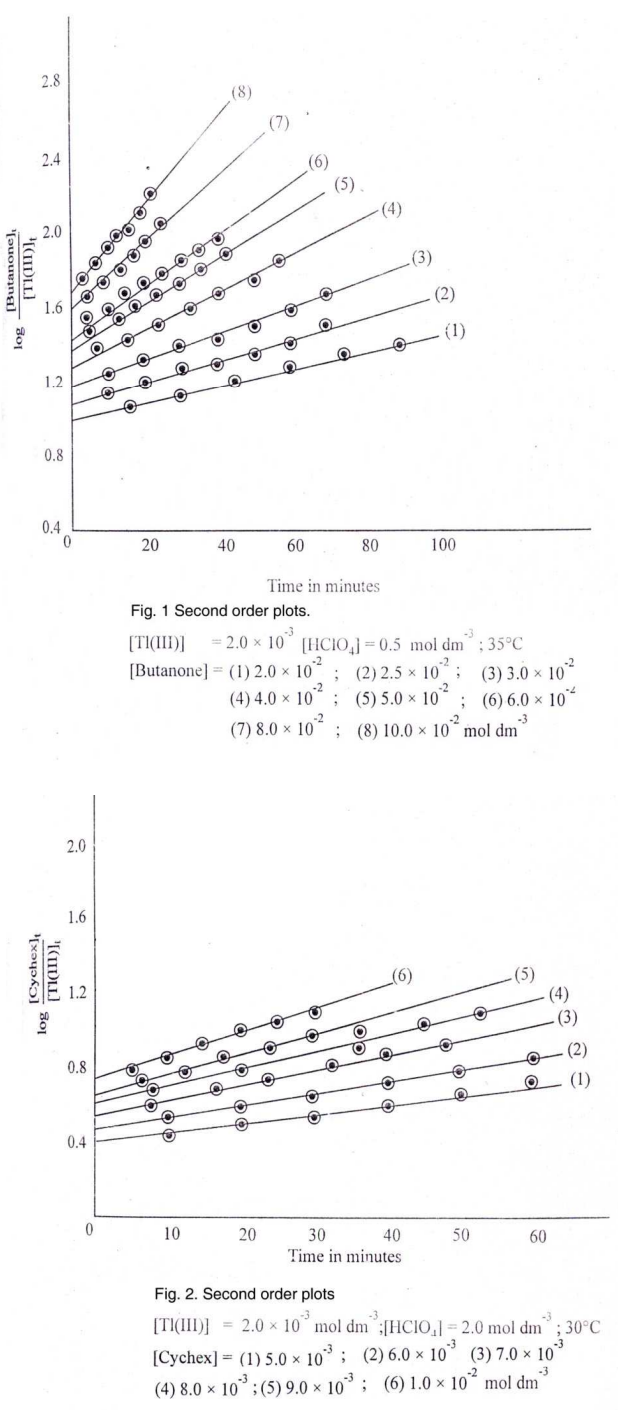

\subsection{Hydrogen Ion Dependence}

Hydrogen ion concentration was varied from 0.5 to 2.0 mol dm ${ }^{-3}$ at $30,35,40$ and $45^{\circ} \mathrm{C}$ by employing perchloric acid at $\mathrm{I}=2.0 \mathrm{~mol} \mathrm{\textrm {dm } ^ { - 3 }}$. Similarly hydrogen ion concentration was varied in case of cyclohexanone at $\mathrm{I}=$ $2.0 \mathrm{~mol} \mathrm{dm}^{-3}$ and 30,35 and $40^{\circ} \mathrm{C}$ respectively. The rate decreases with increasing concentration of hydrogen ion in each case.

\subsection{Effect of Ionic Strength}

The effect of ionic strength (I) on the rate of the reaction was studied by employing lithium perchlorate. However, rate remains unchanged on changing the concentration of lithium perchlorate in both the cases ruling out any effect of ionic strength on the rate of the reaction.

\subsection{Dependence of Thallium (I)}

The concentration of Tl(I) was varied from $1.0 \times 10^{-3}$ to $5.0 \times 10^{-3} \mathrm{~mol} \mathrm{dm}^{-3}$ at constant concentrations of other reaction ingredients. The rate remains unchanged eliminating any possibility of fast equilibrium preceded by the rate controlling step in the reaction mechanism.

The activation parameters such as energy and entropy of activation were calculated to be $(84 \pm 2) \mathrm{kJ} \mathrm{mol}^{-1}$ and $(-1.0$ $\pm 2) \mathrm{JK}^{-1} \mathrm{~mol}^{-1}$ in case of butanone and $(80 \pm 5) \mathrm{kJ} \mathrm{mol}^{-1}$ and $(-5.0 \pm 1.0) \mathrm{JK}^{-1} \mathrm{~mol}^{-1}$ in case of cyclohexanone.

\section{Discussion}

The most important aspect in elucidation of the reaction mechanism in oxidation of ketones by transition metal ion oxidants pertains to the enolization of species of ketones in the rate-determining step. Such reactions are normally catalyzed by hydrogen ion. However, the hydrogen ion dependence in the title reaction is contrary to such an observation as the rate decreases with increasing hydrogen ion concentration. Moreover, the order with respect to the oxidant is also one which again rules out enolization step to be the rate controlling step. Had it not been the situation, the rate would have been controlled by enolization of ketones. Thus the observed hydrogen ion dependence can be correlated to either oxidant or to the substrate.

Thallium (III) perchlorate solutions are sufficiently stable in high acid concentrations $\left(>1.0 \mathrm{~mol} \mathrm{dm}^{-3}\right)$. In lower acid medium, thallium (III) reportedly [20,21] undergoes hydrolysis as represented by equation (1).

$$
\mathrm{Tl}^{3+}+\mathrm{H}_{2} \mathrm{O} \rightleftharpoons \mathrm{K}_{\mathrm{h}} \mathrm{TlOH}^{2+}+\mathrm{H}^{+}
$$

The hydrolysis constant $\left(\mathrm{K}_{\mathrm{h}}\right)$ is reported to be 0.086 and 0.088 at $25^{\circ} \mathrm{C}$ and $30^{\circ} \mathrm{C}$ respectively if enthalpy of hydrolysis to be $69.4 \mathrm{~kJ} \mathrm{~mol}^{-1}$ is any guide. Since the rate decreases with increasing hydrogen ion concentration, the hydrolyzed species $\mathrm{TlOH}^{2+}$ should be more reactive than $\mathrm{Tl}^{3+}$ (aq) species. It is not, however, unusual as $\mathrm{TlOH}^{2+}$ has earlier been considered to be the reactive species in other reactions of thallium (III) [22-25].

Thus the direct interaction of $\mathrm{TlOH}^{2+}$ species with molecular form of ketone appears to be responsible to bring about retarding effect of hydrogen ion concentration in the reaction. Therefore, following mechanism (2)-(4) being in conformity to the experimental observations can be envisaged,

$$
\begin{aligned}
& \mathrm{Tl}^{3+}+\mathrm{H}_{2} \mathrm{O} \rightleftharpoons \mathrm{K}_{\mathrm{h}} \rightleftharpoons \mathrm{TlOH}^{2+}+\mathrm{H}^{+} \\
& \mathrm{TlOH}^{2+}+\text { ketone } \stackrel{\mathrm{K}_{1}}{\rightleftharpoons}\left[\mathrm{TlOH}^{2+} \ldots . \text { ketone }\right] \\
& {\left[\mathrm{TlOH}^{2+} \ldots . . . \text { ketone }\right] \stackrel{\mathrm{k}_{1}{ }^{\prime} \longrightarrow \text { Products }}{\longrightarrow} \text { P }}
\end{aligned}
$$

The loss of thallium (III) leads to the rate law (5) or (6)

$$
-\frac{\mathrm{d}\left[\mathrm{Tl}^{\mathrm{III}}\right]}{\mathrm{dt}}=\frac{\mathrm{k}_{1}^{\prime} \mathrm{K}_{1} \mathrm{~K}_{\mathrm{h}}[\mathrm{Tl}(\mathrm{III})]_{\mathrm{T}}[\text { Ketone }]_{\mathrm{T}}}{\left[\mathrm{H}^{+}\right]+\mathrm{K}_{\mathrm{h}}}
$$

Where $[\mathrm{Tl}(\mathrm{III})]_{\mathrm{T}}$ and $[\text { Ketone }]_{\mathrm{T}}$ are the gross analytical concentrations of thallium (III) and ketone respectively. 

Cyclohexanone by Thallium (III) in Acid Perchlorate Medium- An Appraisal of Keto Form Reactivity

$$
\text { or } \quad \mathrm{k}=\frac{\mathrm{k}_{1}^{\prime} \mathrm{K}_{1} \mathrm{~K}_{\mathrm{h}}}{\left(\left[\mathrm{H}^{+}\right]+\mathrm{K}_{\mathrm{h}}\right)}
$$

where ' $\mathrm{k}$ ' is observed second order rate constant (table 1 and 2) for butanone and cyclohexanone respectively. Since there is neither kinetic nor spectral evidence for formation of an intermediate complex, the equilibrium constant $\mathrm{K}_{1}$ is small, the eqn (6) is further reduced to eqn (7)

$$
\mathrm{k}=\mathrm{k}_{1} \mathrm{~K}_{\mathrm{h}} /\left(\left[\mathrm{H}^{+}\right]+\mathrm{K}_{\mathrm{h}}\right)
$$

Where $\mathrm{k}_{1}{ }^{\prime} \mathrm{K}_{1}=\mathrm{k}_{1}$

The double reciprocal of eqn (7) on rearrangement yields eqn (8)

$$
1 / \mathrm{k}=\left[\mathrm{H}^{+}\right] / \mathrm{k}_{1} \mathrm{~K}_{\mathrm{h}}+1 / \mathrm{k}_{1}
$$

Table 1. Pseudo first order rate constants $\left(k^{\prime}\right)$ and second order rate

\begin{tabular}{|c|c|c|c|}
\hline $\begin{array}{l}10^{3}\left[\mathrm{Tl}^{\mathrm{III}}\right] \\
\mathrm{mol} \mathrm{dm}^{-3}\end{array}$ & $\begin{array}{l}10^{2} \text { [butanone] } \\
\mathrm{mol} \mathrm{dm}^{-3}\end{array}$ & $\begin{array}{l}10^{4}\left(k^{\prime}\right) \\
s^{-1}\end{array}$ & $\begin{array}{l}10^{3}\left(\mathrm{k}_{1}\right) \\
\mathrm{dm}^{3} \mathrm{~mol}^{-1} \mathrm{~s}^{-1}\end{array}$ \\
\hline 1.0 & 5.0 & 4.61 & $9.4(9.2)$ \\
\hline 1.5 & 5.0 & 4.61 & $9.5(9.2)$ \\
\hline 2.0 & 5.0 & 4.61 & $9.6(9.2)$ \\
\hline 2.5 & 5.0 & 4.61 & $9.4(9.2)$ \\
\hline 3.0 & 5.0 & 4.61 & $9.4(9.2)$ \\
\hline 3.5 & 5.0 & 4.61 & $9.4(9.2)$ \\
\hline 4.0 & 5.0 & 4.61 & $9.5(9.2)$ \\
\hline 4.5 & 5.0 & 4.61 & $9.3(9.2)$ \\
\hline 5.0 & 5.0 & 4.61 & $9.2(9.2)$ \\
\hline 1.0 & 10.0 & 9.60 & $9.7(9.6)$ \\
\hline 1.5 & 10.0 & 9.60 & $9.7(9.6)$ \\
\hline 2.0 & 10.0 & 9.60 & $9.8(9.6)$ \\
\hline 2.5 & 10.0 & 9.60 & $9.8(9.8)$ \\
\hline 3.0 & 10.0 & 9.60 & $9.2(9.6)$ \\
\hline 3.5 & 10.0 & 9.60 & $9.3(9.6)$ \\
\hline 4.0 & 10.0 & 9.60 & $9.3(9.6)$ \\
\hline 4.5 & 10.0 & 9.60 & $9.4(9.6)$ \\
\hline 5.0 & 10.0 & 9.60 & $9.0(9.6)$ \\
\hline 2.0 & 2.0 & 9.60 & $9.6(9.2)$ \\
\hline 2.0 & 2.5 & 2.30 & $9.6(9.2)$ \\
\hline 2.0 & 3.0 & 2.88 & $9.8(9.6)$ \\
\hline 2.0 & 3.5 & 3.25 & $9.5(9.3)$ \\
\hline 2.0 & 4.0 & 3.84 & $9.6(9.6)$ \\
\hline 2.0 & 4.5 & 4.17 & $9.6(9.3)$ \\
\hline 2.0 & 5.0 & 4.61 & $9.6(9.2)$ \\
\hline 2.0 & 6.0 & 5.37 & $9.2(9.0)$ \\
\hline 2.0 & 8.0 & 7.36 & $9.6(9.2)$ \\
\hline 2.0 & 10.0 & 9.60 & $9.8(9.6)$ \\
\hline 3.0 & 3.0 & 2.88 & $9.4(9.6)$ \\
\hline 3.0 & 3.5 & 3.36 & $9.3(9.6)$ \\
\hline 3.0 & 4.0 & 3.60 & $9.3(9.1)$ \\
\hline 3.0 & 4.5 & 4.11 & $9.3(9.1)$ \\
\hline 3.0 & 5.0 & 4.61 & $4.61(9.2)$ \\
\hline 3.0 & 6.0 & 5.76 & $9.3(9.6)$ \\
\hline 3.0 & 8.0 & 7.21 & $9.6(9.6)$ \\
\hline 3.0 & 10.0 & 9.60 & $9.2(9.6)$ \\
\hline
\end{tabular}
constants $(k)$ in the reaction of thallium(III) and butanone.

$\left[\mathrm{HClO}_{4}\right]=0.5 \mathrm{~mol} \mathrm{dm}^{-3}, 35^{\circ} \mathrm{C}$

$\mathrm{k}^{\prime}$ values given in parenthesis were calculated from pseudo first order rate constants.
Table 2. Initial rates $\left(k_{i}\right)$, pseudo first order rate constants $\left(k^{\prime}\right)$ and second order rate constants $(k)$ in the reaction of thallium (III) and

\begin{tabular}{|c|c|c|c|c|}
\hline $\begin{array}{l}10^{3}\left[\mathrm{TI}^{\mathrm{III}}\right] \\
\mathrm{mol} \mathrm{dm}^{-3}\end{array}$ & $\begin{array}{l}10^{2} \\
\text { [cyclohexanone] } \\
\text { mol dm }\end{array}$ & $\begin{array}{l}10^{6}\left(k_{i}\right) \\
m^{-1} \\
s^{-1}\end{array}$ & $\begin{array}{l}10^{3}\left(k^{\prime}\right) \\
\mathrm{s}^{-1}\end{array}$ & $\begin{array}{l}0^{2}\left(\mathrm{k}_{1}\right) \\
\mathrm{dm}^{3} \mathrm{~mol} \\
{ }^{1} \mathrm{~s}^{-1}\end{array}$ \\
\hline 1.0 & 0.5 & 0.30 & - & $6.0(6.0)$ \\
\hline 1.5 & 0.5 & 0.46 & - & $6.4(6.1)$ \\
\hline 2.0 & 0.5 & 0.63 & - & $6.4(6.3)$ \\
\hline 2.5 & 0.5 & 0.75 & - & $6.1(6.0)$ \\
\hline 3.0 & 0.5 & 0.92 & - & $5.8(6.1)$ \\
\hline 3.5 & 0.5 & 1.04 & - & $5.8(5.9)$ \\
\hline 4.0 & 0.5 & 1.19 & - & $6.3(6.0)$ \\
\hline 4.5 & 0.5 & 1.38 & - & $6.1(6.1)$ \\
\hline 5.0 & 0.5 & 1.6 & - & $-(5.8)$ \\
\hline 1.0 & 1.0 & 0.60 & - & $6.2(6.0)$ \\
\hline 1.5 & 1.0 & 0.92 & - & $6.4(6.1)$ \\
\hline 2.0 & 1.0 & 1.25 & - & $5.8(6.3)$ \\
\hline 2.5 & 1.0 & 1.42 & - & $5.8(5.7)$ \\
\hline 3.0 & 1.0 & 1.75 & - & $6.0(5.8)$ \\
\hline 3.5 & 1.0 & 2.25 & - & $6.0(6.4)$ \\
\hline 4.0 & 1.0 & 2.33 & - & $5.8(5.8)$ \\
\hline 4.5 & 1.0 & 2.58 & - & $6.3(5.7)$ \\
\hline 5.0 & 1.0 & 3.0 & - & $5.8(6.0)$ \\
\hline 1.0 & 2.0 & - & 1.25 & $6.46 .2 *$ \\
\hline 1.5 & 2.0 & - & 1.25 & $6.26 .2 *$ \\
\hline 2.0 & 2.0 & - & 1.25 & $6.46 .2^{*}$ \\
\hline 2.5 & 2.0 & 3.08 & - & $6.4(6.2)$ \\
\hline 3.0 & 2.0 & 3.76 & - & $6.2(6.3)$ \\
\hline 3.5 & 2.0 & 4.19 & - & $5.8(6.0)$ \\
\hline 4.0 & 2.0 & 5.0 & - & $6.0(6.3)$ \\
\hline 4.5 & 2.0 & 5.41 & - & $6.2(6.0)$ \\
\hline 5.0 & 2.0 & 6.25 & - & $6.4(6.3)$ \\
\hline 2.0 & 0.5 & 0.63 & - & $6.4(6.3)$ \\
\hline 2.0 & 0.6 & 0.75 & - & $5.8(6.3)$ \\
\hline 2.0 & 0.7 & 0.89 & - & $5.8(6.3)$ \\
\hline 2.0 & 0.8 & 0.99 & - & $6.4(6.2)$ \\
\hline 2.0 & 0.9 & 1.11 & - & $6.4(6.2)$ \\
\hline 2.0 & 1.0 & 1.25 & - & $5.8(6.3)$ \\
\hline 2.0 & 2.5 & 2.92 & - & $5.8(5.8)$ \\
\hline 2.0 & 3.0 & 3.54 & - & $6.5(5.9)$ \\
\hline 2.0 & 3.5 & 4.17 & - & $6.2(6.0)$ \\
\hline 2.0 & 4.0 & 4.72 & - & $6.4(5.9)$ \\
\hline 2.0 & 4.5 & 5.42 & - & $6.2(6.0)$ \\
\hline 2.0 & 5.0 & 5.83 & - & $6.0(5.8)$ \\
\hline
\end{tabular}
cyclohexanone

$\left[\mathrm{HClO}_{4}\right]=0.5 \mathrm{~mol} \mathrm{dm}^{-3}, 30^{\circ} \mathrm{C}$

' $\mathrm{k}$ ' values in parenthesis were calculated from initial rates and those with star $\left(^{*}\right)$ were obtained from pseudo first order rate constants.

A plot of $1 / \mathrm{k}$ versus $\left[\mathrm{H}^{+}\right]$was made from equation (8) that yielded a straight line with non-zero intercept (Figs.3 and 4). $10^{2}\left(\mathrm{~K}_{\mathrm{h}}\right)$ was calculated from the gradient and intercept to be $(8.6 \pm 0.2),(7.1 \pm 0.4),(7.7 \pm 0.4)$ and $(7.7$ $\pm 0.4)$ in case of butanone at $30,35,40$ and $45^{\circ} \mathrm{C}$, and $(6.2$ $\pm 1.0),(8.0 \pm 5)$ and $(6.9 \pm 1.0)$ in case of cyclohexanone at 30,35 and $40^{\circ} \mathrm{C}$ respectively at $\mathrm{I}=2.0 \mathrm{~mol} \mathrm{dm}^{-3}$. These $\mathrm{K}_{\mathrm{h}}$ values are in agreement to those reported earlier if ionic strength and temperature are any guide. $10^{2}\left(\mathrm{k}_{1}\right)$ was calculated to be $(5.0 \pm 0.1),(6.7 \pm 0.1),(10 \pm 0.2)$, and $(20$ $\pm 0.2) \mathrm{s}^{-1}$ at $30,35,40$ and $45^{\circ} \mathrm{C}$ respectively for butanone 
and $(33 \pm 3.0),(50 \pm 5.0)$ and $(80 \pm 7.0) \mathrm{s}^{-1}$ at $30,35,40^{\circ} \mathrm{C}$ respectively for cyclohexanone at $\mathrm{I}=2.0 \mathrm{~mol} \mathrm{dm}^{-3}$.
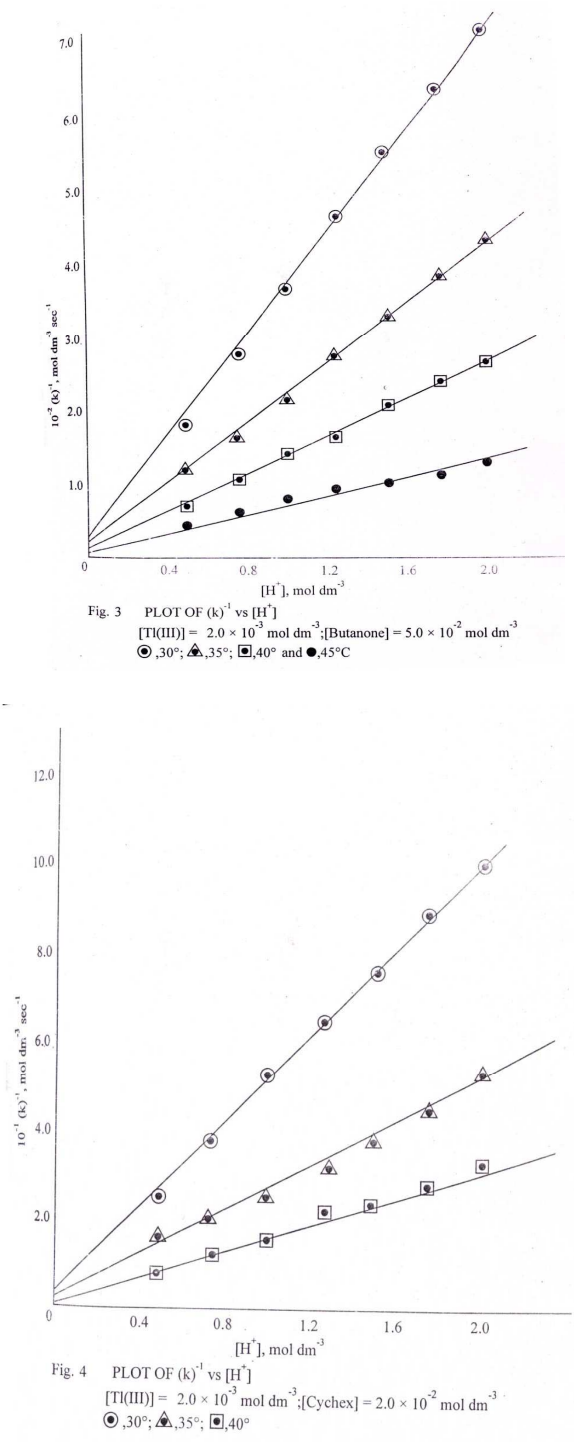

An intramolecular electron transfer through an intermediate complex of thallium (III) is an established mode of electron transfer in most of the reactions of this metal ion oxidant. However, neither kinetic nor spectral evidence supports such a proposition of an intermediate complex. Nevertheless, retarding effect [26-28] of chloride ion qualitatively and indirectly supports our contention of envisaging such an intermidiate complex.

Chloride ion is known to form quantitatively chlorothallium (III) complexes.

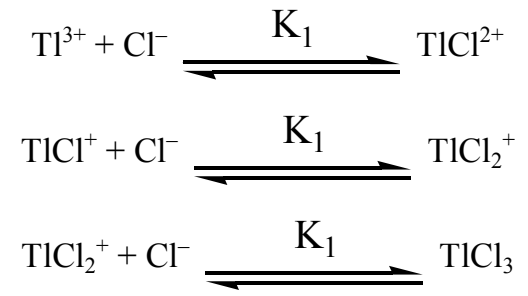

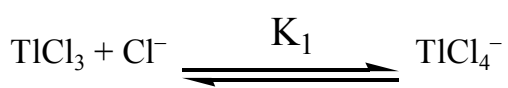

When all the co-ordination sites of the oxidant are saturated by chloride ion, the incorporation of the substrate in co-ordination sites of thallium (III) is blocked chloride ion. Had it not been the situation, substrate would have occupied the co-ordination sites of the metal ion oxidant. Therefore, such an inhibiting effect of chloride ion is an indirect evidence to support complexation between oxidant and substrate. Moreover, the reaction is energetically favorable via formation of an intermediate complex.

So far the mode of electron transfer from the substrate to the oxidant is concerned, attentive schemes-I and II account for the reaction events both for butanone and cyclohexanone respectively.

$$
\begin{aligned}
& \mathrm{Tl}^{3+}+\mathrm{CH}_{3}-\stackrel{\mathrm{O}-\mathrm{R}}{\longrightarrow} \mathrm{CH}_{3}-\|_{\mathrm{C}-\mathrm{R}}^{\mathrm{O}} \\
& \|_{\mathrm{CH}_{3}-\mathrm{C}-\mathrm{R}}^{\mathrm{O}-----\mathrm{Tl}^{3+}} \longrightarrow \mathrm{CH}_{2}-\stackrel{\mathrm{O}}{\oplus}+\dot{\mathrm{R}}+\mathrm{Tl}^{\mathrm{II}}
\end{aligned}
$$

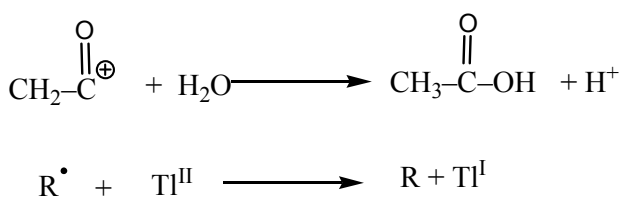

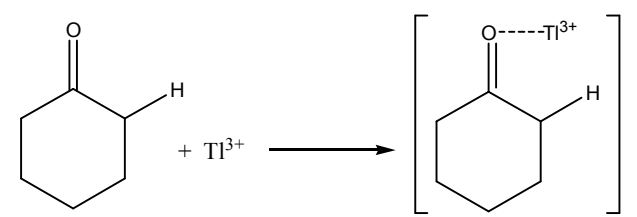

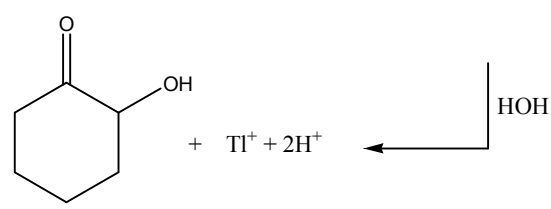

Scheme - II

Since the rate of oxidation of cyclohexanone is less than that of its enolization, this allows cleavage of $\mathrm{C}-\mathrm{H}$ bond in cyclohexanone as in Scheme-II.

Although the radical could not be detected by the conventional polymerization tests presumably due to rapid oxidation of the radical within the solvent cage of the metal ion oxidant. Nevertheless, it is still a possibility to postulate its formation. If radical formation is considered, the formation of $\mathrm{Tl}^{\mathrm{II}}$ can not be ruled out. Since $\mathrm{Tl}^{\mathrm{II}}$ was not detected, it is in all probability reacted immediately as the former is stronger oxidant than $\mathrm{Tl}^{\mathrm{III}}$ if redox potentials of the couples $\mathrm{Tl}^{\mathrm{III}} / \mathrm{Tl}^{\mathrm{I}}$ and $\mathrm{Tl}^{\mathrm{II}} / \mathrm{Tl}^{\mathrm{I}}$ are any guide.

So far as the comparative pattern of reactivity of these 
ketones is concerned, cyclohexanone is more reactive than butanone towards thallium (III) in acid solution as is apparent from the second order rate constants (Tables 1 and 2). Since angular strain of equatorial hydrogens of carbonyl oxygen and also change of hybridization of oxygen appear to be the reason of more reactivity of cyclohexanone than that of butanone.

Therefore, the proposals as suggested on the premise of experimental observations are more logical in the light of the following observations:

(i) The major oxidation product of butanone is acetic acid which is not further oxidized by thallium (III).

(ii) The kinetic parameters such as initial rates, pseudo first order and second order rate constants conform to the $1: 1$ stoichiometry of the reaction. Second order rate constants obtained under stoichiometric conditions are in close agreement with the second order rate constants evaluated from initial rates and pseudo first order rate constants, respectively. Such an observation certainly eliminates any possibility of enolization of the ketone to be the rate controlling step.

(iii) If oxidation potentials [29] of $\mathrm{Tl}^{3+} / \mathrm{Tl}^{+}$and $\mathrm{Tl}^{2+} /$ $\mathrm{T}^{+}$redox couples are taken into account, $\mathrm{Tl}(\mathrm{II})$ is certainly a stronger oxidant than thallium (III). It is, therefore, probable that $\mathrm{Tl}(\mathrm{II})$ intermediate, in the solvent cage to immediately reacts with substrate free radical. This appears to be the reason of not finding free radical formation in the reaction kinetics.

\section{References}

[1] M. Pechal, J. Vojtko, J. Kubena and M. Hrusovsky, "Kinetics of the oxidation of aliphatic ketones by thallic salts in sulfuric acid medium", React. Kinet. Catal. Lett., vol. 20, pp. 151-155, 1982.

[2] K. Vijayamohan, P.R. Rao and E.V. Sundaram, "Nbromosaccharin as an oxidizing agent-A kinetic study using aliphatic and cyclic ketones in aqueous acetic acid", J. Ind. Chem. Soc., vol. 61, pp. 225-228, 1984.

[3] M. Gupta, S.K. Saha and P. Banerjee, "Kinetics and mechanism of the oxidation of some cyclic and acyclic ketones by dodecatungstocobaltate(III)- A comparative study", Int. J. Chem. Kinet., vol. 22, pp. 81-94, 1990.

[4] B. Singh, B.B.L. Saxena and A.K. Samant, "Kinetics and mechanism of the oxidation of some aliphatic ketones by nbromoacetamide in acidic media", Tetrahderon, vol. 40, pp. 3321-3324, 1984.

[5] D.S. Mahadevappa, K. Mohan and S. Ananda, "Oxidation of aliphatic ketones by bromamine-B; A kinetic study", Tetrahderon, vol. 42, pp. 4857-4866, 1986.

[6] N.K. Murthy, C.H.S. Reddy and E.V. Sundaram, "Kinetics and mechanism of acid bromated oxidation of aliphatic, aralkyl \& alicyclic ketones", Ind. J. Chem. Sect (A), vol. 28, pp. 288-291, 1989.
[7] P. Manikyamba, "Structural effects in the oxidation of ketones by acid iodate", Collect. Czech. Chem. Commun., vol. 56, pp. 1279-1286, 1991 .

[8] K.K. Banerji, M.P. Nath and G.V. Bakore, "A kinetic investigation of oxidation of ethyl methyl ketone by manganese (III) sulphate", Bull. Chem. Soc. Jpn., vol. 43, pp. 2027-2029, 1970.

[9] G. Manivannan and P. Maruthamuthu, "Kinetics and mechanism of oxidation of aliphatic and aromatic ketones by peroxomonosulphate", J. Chem. Soc. Perkin, Tran 2, pp. 565-568, 1986.

[10] M.P. Nath and K.K. Banerji, "Kinetics \& mechanism of oxidation of acetone, butanone, pentan-2-one, 3methylbutan-2-one, hexan-2-one \& 4-methylpentan-2-one by acid permanganate", Ind. J. Chem. Sec. (A), vol. 14, pp. 660-662, 1976.

[11] M. P. Nath and K.K. Banerji, "Kinetics and mechanisms of the oxidation of methyl aryl ketones by acid permanganate", Aust. J. Chem., vol. 29, pp. 1939-1945, 1976.

[12] P.S. Radhakrishnamurti and M.D.P. Rao, "Oxidation of aliphatic ketones, substituted acetophenones \& cyclic ketones by potassium permanganate", Ind. J. Chem. Sect. (A), vol. 15, pp. 524-527, 1977.

[13] P.K. Sen, G. Mukhopadhyay and K.K. Sengupta, "Kinetics and mechanism of the oxidation of alkyl and aryl methyl ketones by permanganate ion in aqueous ethanoic acid", Trans. Met. Chem., vol. 23, pp. 577-582, 1998.

[14] A. Ramesh, B. Syamasunder and P.S. Radhakrishnamurti, "Kinetics and mechanism of oxidation of methyl ethyl ketone by iodine mono bromide catalyzed by $\mathrm{Hg}$ (II) and $\mathrm{N}$-bromophthalimide in acid medium", Oxid. Commun., vol. 31 (3), pp. 554-560, 2008.

[15] A. Gupta, M.K. Singh and H.S. Singh, "Iridium (III) chloride catalyzed oxidation of ketones by cerium (IV) sulfate in aqueous sulfuric acid medium. A kinetic study", Oxid. Commun., vol. 30 (3), pp. 633-640, 2007.

[16] Liang. Jeng-Jong and Chen. Chun-Hsiang, "Catalytic oxidation of toluene and methyl ethyl ketone over La-SrMn perovskite catalysts", Zhongguo Huanjing Gongcheny Xuekan, vol. 15 (2), pp. 111-119, 2005.

[17] I.M. Kolthoff and R. Belcher, Volumetric Analysis, Interscience, New York, vol. 3, 1957, pp. 370.

[18] H.G.S. Sengar, and Y.K. Gupta, "Kinetics of silver catalysed oxidation of Tl (I) by persulphate", J. Ind. Chem. Soc., vol. 43, pp. 223-234, 1966.

[19] M. Latshaw, “A simple tangentimeter”, J. Am. Chem. Soc., vol. 47, pp. 793-794, 1925.

[20] A.G. Lee, Chemistry of Thallium, Elsevier, London, 1971.

[21] G. Nord, "Oxidation of some tris (2,2'-bipyridyl) and tris (1,10-phenenthroline) osmium (II) salts by thallium (III) in aqueous acid", Inorg. Chem., vol. 15, pp. 1921-1925, 1976 and references cited therein.

[22] J.O. Wear, "The oxidation of uranium (IV) by thallium (III) over an extended concentration range in aqueous perchloric acid solutions", J. Chem. Soc., pp. 5596-5601, 1965.

[23] D.H. Irvine, "The Kinetics of the reduction of thallium (III) 
by the tris dipyridylosmium (II) ion in aqueous perchloric acid" J. Chem. Soc., pp. 1841-1845, 1957.

[24] A.M. Armstrong and J. Halpern, "Kinetics of the oxidation of mercury (I) by thallium (III) in aqueous solution", Can. J. Chem., vol. 35, pp. 1020-1030, 1957 and references cited therein.

[25] H.N. Halvorson and J. Halpern, "Kinetics of the reaction between formic acid and thallium (III) in aqueous solution", J. Am. Chem. Soc., vol. 78, pp. 5562-5566, 1956.

[26] P.D. Sharma and Y.K. Gupta, "Reduction of chlorothallium (III) complexes by arsenic (III)", Aust. J. Chem., vol. 26, pp.
2115-2122, 1973.

[27] P.D. Sharma and Y.K. Gupta, "Kinetics and mechanism of electron transfer reactions of aquo \& coordinated thallium (III): Reduction of chloro-thallium (III) complexes by antimony (III)", Ind. J. Chem., vol. 12, pp. 100-102, 1974.

[28] P.D. Sharma and Y.K. Gupta, "Kinetics and mechanism of the reduction of thallium (III) by arsenic (III) in perchlorate acid solution", J. Chem. Soc. Dalton Trans., pp. 52-55, 1972 and references cited therein.

[29] W.M. Latimer, Oxidation Potentials, 2nd. ed., Prentice Hall, New York 1952. 